\title{
CRESCIMENTO RADICULAR DE MUDAS DE COUVE-FLOR PRODUZIDAS EM DIFERENTES SUBSTRATOS DE PRODUÇÃO AGROECOLOGICA
}

\author{
Julio Cesar Gradice Saluci ${ }^{1}$ \\ Mário Euclides Pechara da Costa Jaeggi² \\ Maxwel Rodrigues Nascimento ${ }^{3}$ \\ Diego Rogério Ferraz ${ }^{4}$ \\ Israel Martins Pereira ${ }^{5}$ \\ Rebyson Bissaco Guidinelli ${ }^{6}$ \\ Alex Justino Zacarias ${ }^{7}$ \\ Rogério Range Rodrigues ${ }^{8}$ \\ Samuel Ferreira da Silva ${ }^{9}$ \\ Wallace Luís de Lima $^{10}$
}

\begin{abstract}
Resumo: Este trabalho teve como objetivo avaliar o desempenho de mudas de couve flor, semeadas em diferentes substratos: e concentrações orgânicas formuladas a partir de matéria prima disponível na região. O estudo foi desenhado no delineamento inteiramente casualizado com sete repetições considerando uma planta por repetição, em esquema fatorial $4 \times 4$, quatro substratos e quatro concentrações os tratamentos foram quatro tipos de substratos sendo um comercial comumente utilizado para produção de mudas de hortaliças e três orgânicos de produção agroecológica, ambos produzidos no setor de agroecologia do ifescampus de alegre, sendo: S1- Composto orgânico produzido pelo processo de compostagem de restos de poda de jardim e esterco bovina fresco, de acordo com a metodologia de (SOUZA et al., 2013); S2Vermicomposto produzido com o composto orgânico no qual foi inserido minhocas Eisenia foetida para realizar o processo de vermicompostagem e S3 - Composto orgânico com cinzas de madeira + restos de poda de jardins + esterco bovino, compostado em sistemas de pilhas. As concentrações foram 25, 50, 75 e $100 \%$ de substrato completados com volumoso de terra de barranco característica de horizonte c, completados em volumes. Os substratos orgânicos apresentaram bons desenvolvimento de raiz para as mudas de couve flor.
\end{abstract}

Palavras-chave: Biometria; Compostagem; Resíduo orgânico.

\footnotetext{
1 Tecnologia em cafeicultura/Instituto Federal do Espírito Santo, Brasil. E-mail: juliosaluci@gmail.com.

2 Produção vegetal/Universidade Federal Norte Fluminense, Brasil. E-mail: mariopechara@hotmail.com.

3 Produção vegetal/Universidade Federal Norte Fluminense, Brasil. E-mail: maxwel.m88@gmail.com.

${ }^{4}$ Agroecologia/Instituto Federal do Espírito Santo, Brasil. E-mail: diegofvalim@hotmail.com.

5 Tecnologia em cafeicultura/Instituto Federal do Espírito Santo, Brasil. E-mail: israelmartins80@gmail.com.

6 Tecnologia em cafeicultura/Instituto Federal do Espírito Santo, Brasil. E-mail: rebysonguidinelle@gmail.com.

7 Tecnologia em cafeicultura/Instituto Federal do Espírito Santo, Brasil. E-mail: alexjustino12@gmail.com. com.

8 Produção vegetal/Universidade Federal de Lavras, Brasil. E-mail: rogeriorr7@hotmail.com.

${ }^{9}$ Produção vegetal/Universidade Federal do Espírito Santo, Brasil. E-mail: samuelfd.silva@yahoo.com.br.

10 Instituto Federal do Espírito Santo, Brasil. E-mail: wallace@ifes.edu.br.
} 